Investigation, treatment and prognosis of bronchial carcinoma in the Yorkshire region of England 1976-1983. Brf Cancer 1990;61:579-83.

3 Watkin SW, Hayhurst GK, Green JA. Time trends in the outcome of lung cancer management: a population study of 9090 cases. Br $\mathcal{F}$ Cancer 1990;61:590-6.
4 Lapham R, Waugh NR. An audit of the quality of cancer registration data. Br $\mathcal{F}$ Cancer 1992;66:552-4.

5 Yorkshire Regional Cancer Organisation. Cancer in Yorkshire. Lung cancer. Leeds: YRCO, 1993 Cancer registry report series, no. 1

\title{
Socioeconomic status: developing a quantitative, community based index in rural Kashmir
}

\author{
Timothy D Dye, Richard V Lee
}

The concepts of socioeconomic status (SES) and social class, and their relation to differential rates of death and disease in developed countries, are essential to understanding the social nature and context of sickness and health care in western societies. ${ }^{12}$ The operational concept of socioeconomic status, however, and how it relates to disease is often ambiguous. In many developing countries, where local economies differ from western industrial economies, socioeconomic status measured by western concepts (for example, monetary income) may be irrelevant and inaccurate. ${ }^{2}$ Culturally appropriate, community based socioeconomic indices that reflect differential access to economic assets could elucidate control of the stock of wealth, rather than the flow of wealth. ${ }^{2}$ Furthermore, such indices would enhance the utility of integrating concepts from medical anthropology and social epidemiology in addressing health research in developing countries. These measures subsequently could be used in epidemiological analyses of morbidity and mortality in developing countries.

Socioeconomic status has been directly implicated in the epidemiology of childhood diarrhoea in other studies, ${ }^{3}$ and indirectly implicated with diarrhoea as a correlate of other sociocultural risk factors. ${ }^{45} \mathrm{We}$ were interested in investigating the relationship between access to useful village economic resources (for example, livestock) and the prevalence of childhood diarrhoea in a remote Kashmiri Himalayan village.

Methods: This study was conducted in one of several isolated villages of the Kashmiri Himalayas. Mothers in 23 households were interviewed about their children's health, particularly their children's recent diarrhoeal history, and about household land and animal ownership. To ascertain a measure of socioeconomic status, we constructed an index based on ownership of the two most economically productive animals in this region - cows and sheep.

Socioeconomic status (SES) construction and household diarrhoea prevalence

\begin{tabular}{lllll}
\hline SES category & Animal ownership & $\begin{array}{l}\text { No in } \\
\text { category }\end{array}$ & $\begin{array}{l}1+\text { children } \\
\text { with diarrhoea* }\end{array}$ & OR \\
\hline High & $\geqslant 2$ cows and $\geqslant 3$ sheep & 7 & $85 \cdot 7(6)$ & $3 \cdot 6$ \\
Middle & $\geqslant 2$ cows or $\geqslant 3$ sheep & 8 & $75 \cdot 0(6)$ & 1.8 \\
Low & $<2$ cows and <3 sheep & 8 & $62 \cdot 5(5)$ & 1.0 \\
\hline
\end{tabular}

* Diarrhoea in household children within the prior three months.

Households were divided into three groups according to ownership of more or less than the median number of cows and sheep for the village (table). Diarrhoeal history was provided by the mothers using critical events anchoring to retrospectively measure childhood diarrhoea during the previous three months. Because of the difficulties associated with retrospective recall of diarrhoeal episodes, we structured questions to assess prevalence using conceptually useful time anchors (for example, has the child had diarrhoea since Ramadan) rather than actual time frames of interest (for example three months before the interview). Although we had a working knowledge of some of the local vocabulary, we used an interpreter fluent in English, Kashmiri, and the local dialect and taped interviews to verify translation accuracy with other interpreters. Our project, conducted with the cooperation of the Sher-I-Kashmir Medical Institute, was approved by the SUNY-Buffalo Institutional Review Board.

Results: As shown in the table, seven households were considered high SES, eight were considered low SES, and the remaining eight households represented middle SES.

The prevalence of childhood diarrhoea in the previous three months was highest among children in the high SES group $(\mathrm{OR}=3.6)$, followed by children in the middle SES group $(\mathrm{OR}=1.8)$, and finally by children in the low $\mathrm{SES}$ group $(\mathrm{OR}=1 \cdot 0)$. Furthermore, boys were more likely to have had diarrhoea during the prior three months than were girls $(54.3 \%$ and $32 \cdot 7 \%$, respectively).

Discussion: The prevalence of childhood diarrhoea in this Kashmiri village was highest among children in the "wealthiest" households. This finding is partially explained by the construct of the SES index itself: children, particularly boys, in high SES households were exposed to more animals and therefore to more parasites which cause diarrhoea. Furthermore, as the typical Kashmiri house is a three storey dwelling with the animals housed on the first floor, children in high SES families (or, families with a greater number of animal resources) are at highest risk of diarrhoea. Kashmiri boys, who are responsible for much of the animal care, are at highest risk for diarrhoea in this village. The prevalence of childhood diarrhoea in this area, therefore, was associated with greater animal exposure and therefore with greater control of economic resources. We con- 
sider our findings suggestive and somewhat unexpected, and we intend to explore the associations between animal ownership, housing style, and diarrhoea prevalence in future studies in the area. Furthermore, we hope to explore other environmental exposures (for example, source and storage of drinking water) which may also account for the variations in diarrhoea prevalence that we observed.
1 Liberatos P, Link BG, Kelsey J. The measurement of social class in epidemiology. Epidemiol Rev 1988;10:87-121.

2 Applebaum $\mathrm{H}$. Economic anthropology and the anthropolog of work. In: Applebaum $\mathrm{H}$, ed. Perspectives in cultural anthropology. Albany: State University of New York Press,

3 Coetzer PW, Kroukamp LM. Diarrhoeal disease: epidemiology and intervention. S Afr Med F 1989;76:465-72.

4 Bertrand WE, Walmus BF. Maternal knowledge, attitudes, and practice as predictors of diarrhoeal disease in young children. Int $f$ Epidemiol 1983;12:205-10.

5 Manderson L. Socioeconomic and cultural correlates of gastroenteritis amongst infants and small children in Malaysia. f Trop Pediatr 1981;27:166-76. 